\title{
Covid-19 Pandemic and Its Influence on Social Health Risk Behaviour Change Among Motorcycle Riders in the Transport Industry in Kimili Subcounty, Bungoma County, Kenya
}

\author{
Kato Masika Erastus \\ Masinde Muliro University of Science and Technology, \\ P.O. Box 190-50100, Kakamega, Kenya \\ *Corresponding author details: Kato Masika Erastus; erastusmasika@gmail.com
}

\begin{abstract}
Most urban centres and cities globally are vulnerable to the fast spread of Covid-19 due to their high population and many interactive activities including movement of people. The transport industry has been targeted in many parts of the world in the effort to curb the spread of pandemic as it is believed to be the main conduit of the spread of the pandemic. However, the lockdown of major cities all over the world has led to the development of under ways to facilitate illegal movement of people in and out of the lockdown epicentre cities. In Kenya for instance Nairobi and Mombasa which are believed to be the main epicentres of the spread of the Covid-19 pandemic were put under lockdown by the government of Kenya for three months. Consequently, the government through the ministry of health banned motorists especially public transport vehicles from entering and leaving the epicentre cities. During the lockdown motorcycle became the major mode of public transport illegally sneaking people in and out of these cities thus endangering lives of many Kenyans as they aided in the spread of the pandemic. The lifting of the lockdown of Mombasa and Nairobi has seen tremendous rise in infections and even deaths doubling the previous statistics. The objective of this study was therefore to investigate Covid-19 pandemic and its influence on the social risk behaviour change among motorcycle riders in the transport industry in Kimilili Sub county Bungoma County Kenya. The study population were all the motorcycle riders within Kimilili town. The sample size comprised of 60 motor bike riders selected through simple random sampling from 12 motorcycle stage points in Kimilili town. The study adopted quantitative research design where descriptive survey was employed. Simple structured questionnaire was developed and administered to the respondents. Data was collected and analyzed through descriptive statistics and presented in tables of frequencies and percentages. The results revealed that motorbike riders had failed to comply with the ministry of health guidelines in the transport industry to help fight the spread of Covid-19 pandemic. The extent to which the respondents complied with the government regulations was generally low. Therefore, the noncompliance behaviour of bike motorists to the government directives was a serious social health risk behaviour that the ministry of health should address to minimise the spread of Covid-19 through motorbike transport system in Kenya.
\end{abstract}

Keywords: covid-19 pandemic; social health risk behaviour; motor cycle riders

\section{INTRODUCTION}

In Kenya today the transport industry has immensely embraced motorcycle transport system which has revolutionalized the entire industry. Most people are now using motorcycle mode of transport (commonly known as boda boda in East Africa to get to the doorsteps of their houses in the interior and remote parts of the country where other forms of public transport may not access. Boda boda mode of transport is a readily accessible and reliable mode of transport that today is transforming lives of millions of unemployed youths and boosting the nations' GDP. The poor segments of the society prefer motorcycle riding which is cheap and even faster. In most urban areas where we have bus terminus, motorbike riders are able to pick passengers alighting from major cities to their rural homes deep in villages in good time. However, during this Covid-19 dispensation, motorcycle transport system is now being feared to be the main conduit of the spread of the Covid-19 pandemic not only in Kenya but in the entire region of East Africa and other parts of Africa like Nigeria and Cameroon; where use of boda boda is a common mode of transport (Kumar, 2011). This study investigated the influence of Covid-19 pandemic on social risk behaviour change such as the hygiene practices as directed by the ministry of health, among the motorcycle riders in Kimilili Sub County Kenya. The results revealed that 25 (41.7 \%) of the respondents shook hands with their friends, 27 (45\%) wore protective gear, 24 (40\%) always kept social distance, 21 (35\%) washed hands regularly with soap, $28(46.7 \%)$ engaged their passengers in conversation while riding, 14 (23.3\%) maintained the capacity of 1 passenger per trip and $15(25 \%)$ were able to sanitize their passengers. On the contrary 35(58.3\% of the respondents did not shake hands with each other, 33 (55\%) did not wear protective gear, 36 (60\%) did not always keep social distance, $39(65 \%)$ did not wash hands regularly with soap, $32(53.3 \%)$ never engage their passengers in conversation while riding, 46 (76.7 \%) never maintained the capacity of 1 passenger per trip and 45 (75\%) were not able to sanitize their passengers. From the data given the motorbike riders failed to comply with the ministry 
guidelines in the transport industry as compliance statistics were generally lower than noncompliance statistics. Therefore, the noncompliance behaviour to the government directives among the motorbike riders posed serious social health risk behaviour to the members of the public. The ministry of health should hence address the social health risk behaviour among the riders to minimise the spread of Covid-19.

\section{BACKGROUND TO THE STUDY}

Social health risk behaviour basically is the malpractice in keeping hygiene while interacting with people from various health backgrounds to avoid infection and spread of diseases. Such social hygiene malpractices in the Covid- 19 dispensation include: failure to maintain physical distance with people, failure to wash hands with soap or sanitizers, greeting each other through handshake, sharing of clothes, unprotected sneezing in public, attending meeting in crowded places, lack of masks and protective gear, failure to sanitize work environment and even passengers, avoiding skin contact with passengers and unnecessary movements. These social hygiene practices are clearly stipulated in the directives provided by the ministry of health and transport in Kenya to be followed by all citizens and more importantly the transport industry operators. These are washing of hands and maintaining personal hygiene, avoiding skin contact, wearing protective clothes and masks and keeping physical distance (Irandu, 2020).

Globally public transport industry has been targeted as a key strategic sector of focus to contain the spread of the Covid-19 pandemic as it is alleged that transport industry is the main agent of the spread of the pandemic. The reduction of the number of passengers in public passenger vehicles and the implementation of social health rules and guidelines can help to contain the spread of covid-19. In cities under lockdown, motorbikes and bicycles have been embraced to reduce congestion in public vehicles in the developed countries. Bicycles have proved to be a safer mode of transport in cities such as London and New York where city bike ridership increased by $67 \%$ in March 2020 (Irandu, 2020). In most parts of the world stringent measures have been undertaken to regulate the transport industry to decongest vehicles and minimise the exposure of the passengers to the risk of being infected by Covid- 19 . In the Chinese city of Wuhan, public transport was suspended during the first phase of the pandemic to control the movement of people within the city as to contain the spread of Covid-19. Measures such as provision of information and creation of awareness to the public, training of the staff in the industry, provision of protective gear and sanitizers, regular health checkups were key measures that most governments enacted in the transport industry in the developed world to check the spread of Covid-19 (Irandu, 2020).

The government of Kenya has issued stern warning to the public transport sector to adhere to the ministry of health guidelines especially the bike motorists who are believed to be the main conduit of the spread of Covid-19 pandemic. According Kimuyu (30th march, 2020), the boda boda transport industry was highly responsible for the fast spread of Covid-19 pandemic locally through communities. Therefore, drastic measures were quickly undertaken to tame the boda boda transport industry as to contain the spread of the pandemic in Kenya.

In the developing countries however, little has been achieved to ensure the measures to curb Covid -19 in the transport sector are implemented fully and supervised. The public transport industry operators have lacked crucial information and skills consequently they have flouted the laid down regulations against covid-19 pandemic and this could be the reason why the pandemic curve has failed to flatten as statistics continue to show alarming rates of infection in Kenya today. The motorbike transport which is highly preferred by most poor people in Kenya, Uganda and Nigeria is now being considered as a major threat against containing of the spread of Covid-19 pandemic as laws are continually being broken by the riders regardless of police surveillance (Kumar, 2011). Flouting of traffic rules by bike motorists has led to the increase in road accidents resulting in deaths and pollution of the environment which has become normal way of life. During the lockdown of Nairobi, Mombasa, Kilifi and Kwale, a booming season for boda boda who took the monopoly in the transport sector to serve town dwellers without observing the covid-19 pandemic rules such wearing of protective clothes and masks, keeping social distance and avoiding crowded places was witnessed. The government therefore sounded a stern warning to boda boda operators who flouted the covid-19 pandemic rules (Ministry of Health, 2020). The concern of the public health is that boda bodas are associated with increased crime, accidents, flouting of rules and should therefore be controlled through registration and creation of specific stages for the operators. The root cause of this kind of social risk behaviour is cited as lack of formal employment, substance abuse, impunity, weak law enforcement system and high cost of living (National Crime Research Centre, 2018). This explains why there is insignificant social health risk behaviour change among the motor bike riders even in the Covid-19 dispensation. Due to prevalence of poverty the riders cannot afford to buy sanitizers, protective gears, attend regular medical checkups and more importantly their criminal tendencies.

In Uganda boda boda transport system was put to a halt from transporting passengers and only allowed to transport goods for fear of fast spread of covid -19 pandemic. The president of Uganda banned boda boda transport from carrying passengers for fear of the quick spread of the pandemic in Uganda especially deep in the communities where boda boda easily accessed. It was very difficult to control the operators of boda boda during this Covid- 19 pandemic. The government of Uganda was in talks with the boda boda operators to come up with safety measures to curb the spread of the Covid-19 in the transport industry such as the proposed the anti - corona shield and one passenger capacity for a motorbike (Lamu, $21^{\text {st }}$ July 2020). On the other hand, in Kenya the governor of Machakos County Dr. Alfred Mutua also banned the use of boda bodas in the transport industry for fear of the spread of the Covid-19 due to the nature of the operators who are ever flouting the traffic rules and aiding criminals in transportation of miraa and muguka, the outlawed products (Agutu, 2020).

It is against the background of the ministry of health and that of transport directives to combat the spread of Covid19 pandemic that this study is anchored. The study sought to investigate the prevalence of social health risk practices among motorbike riders in the public transport industry in Kimilili town which is one of the most populous sub county towns in Bungoma County, Kenya.

\section{STATEMENT OF THE PROBLEM}

Following the ministry of health and that of transport and communication directives, all players in the transport industry were required to strictly observe the laid down regulations such as sanitization of public transport vehicles, washing of hands, wearing of protective clothes, wearing of masks and avoiding skin contacts and keeping social distance. However, the transport sector especially the motor bike riders have flouted the basic rules by the ministry of health hence undermined the government effort 
to fight against the Covid-19. This study investigated the extent to which the motorbike transport industry had practised the basic social health hygiene practices to help contain the spread the Covid-19 pandemic. This was in response to the allegations by the government that the fast spread of Covid-19 in the rural areas was highly facilitated by the health malpractices perpetrated by motorbike riders.

\section{OBJECTIVE OF THE STUDY}

The specific objective of the study was to establish the extent to which Covid-19 pandemic had influenced social health risk behaviour change to curb the spread Covid-19 pandemic among motor bike public transport industry in Kimilili sub county, Bungoma County.

\section{RESEARCH QUESTION}

To what extent has the Covid-19 pandemic influenced social health risk behaviour change among the motorbike riders to help curb the spread of pandemic in Kimilili sub county, Bungoma county Kenya?

\section{Methodology}

This study adopted quantitative research design where descriptive survey was employed. The target population of the study were all the motorbike riders in Kimilili town who offer transport services to the public. The sample size was 60 respondents selected through simple random sampling from 12 main stage points. Five respondents were purposively selected from each stage point. A simple self-administered questionnaire was developed for data collection. Data was analyzed and presented in tables of percentages and frequencies.

\section{Target Population and Sample Size}

The target population of this study were all the motorbike riders in Kimilili town offering public transport service in town at 12 main stage points. Five respondents were purposively selected from each stage giving a sample size of 60 respondents as shown in table 1.

TABLE 1: Sample Matrix

\begin{tabular}{|l|c|}
\hline \multicolumn{1}{|c|}{ Main Motor Bike Stage Points } & Sample Size \\
\hline Dcs Place Stage & 5 \\
\hline Kaptola Junction Stage & 5 \\
\hline Hospital Gate Stage & 5 \\
\hline Riziki Supermarket Stage & 5 \\
\hline Kapsokwony Junction Stage & 5 \\
\hline Kitale T- Junction Stage & 5 \\
\hline Misikhu Line Junction & 5 \\
\hline Coop Bank Stage & 5 \\
\hline Main Bus Terminus Stage & 5 \\
\hline Bokoli Junction Stage & $\mathbf{6 0}$ \\
\hline \multicolumn{1}{c|}{ Total } & \\
\hline
\end{tabular}

Source: Field Data

\section{RESULTS AND DISCUSSIONS}

\section{Response rate and demographic background of the respondents}

The respondents were aged between 20 and 50 years and were all males. Most of those who were young were former school leavers and school drop outs both at primary and secondary school levels who relied on the bikes for livelihood while the elderly were also peasant farmers.
All respondents participated in the study and responded to the simple questionnaire items successfully. Therefore, the response rate was $100 \%$.

The study sought to establish the extent to which Covid-19 pandemic had influenced social health behaviour change among the motor bike transporters in Kimilili Sub County. The responses are tabulated and presented as indicated in table 2.

TABLE 2: Motorbike Riders' Responses on Social Health Risk Behaviour Change.

\begin{tabular}{|l|c|c|c|c|c|}
\hline \multicolumn{1}{|c|}{ STATEMENTS } & Yes & \% & No & \% & Total \\
\hline Do you greet your friends through handshake? & 25 & 41.7 & 35 & 58.3 & 60 \\
\hline Do you use protective gear when riding? & 27 & 45 & 33 & 55 & 60 \\
\hline Do you observe physical distance at stage point with your friends? & 24 & 40 & 36 & 60 & 60 \\
\hline Do you wash your hands after every trip you make? & 21 & 35 & 39 & 65 & 60 \\
\hline Do you engage your customer in conversation while riding & 28 & 46.7 & 32 & 53.3 & 60 \\
\hline Do you always maintain one passenger capacity at a time? & 14 & 23.3 & 46 & 76.7 & 60 \\
\hline Do you sanitize your passengers before the ride? & 15 & 25 & 45 & 75 & 60 \\
\hline
\end{tabular}

Source: Field Data

Results in table 2 reveal that respondents who agreed to have greeted friends through handshake by 'YES' response were 25 (41.7\%) while those who responded 'NO' were 35 (58.3\%). Therefore, those who responded NO were more than those who responded YES.
Although over $50 \%$ of the respondents complied with the government regulation of avoiding greetings through handshake, quite a considerable number were yet to comply. Such a large number (41.7\%) can have devastating impact on social health and pose the risk of 
spreading the Covid-19 pandemic through continued shaking of hands. Shaking of hands is a long time African social cultural practice that may take time to be eradicated especially through serious awareness and sensitization campaigns among the motorbike operators as well as the general public.

Respondents who responded 'YES' on the research question, 'Do you have protective gear when riding?' were 27 (45\%) while those who responded 'NO' were 33 (55\%). Therefore, those who responded NO were more than those who responded YES. This implies that protective gear did not matter among all the riders. This could be attributed by the fact that most riders could not afford to buy the clothes. This is indeed a challenge among the motorbike riders as it exposes them to Covid-19. There is a possibility of skin contact between the rider and passengers who may be victims of Covid-19. In view of this pandemic, the government should help the bike riders secure protective clothes through financial assistance to subsidize the costs. This finding on protective clothes can be observed in most towns in Kenya today where the riders expose themselves to health risk riding. The ministry of health observed this social health risk behaviour during the lockdown of Mombasa and Nairobi cities in Kenya, consequently has sounded warning regarding the flouting of the health directive on motor bike riding on $9^{\text {th }}$ April, 2020.

Responses on the question: 'Do you observe physical distance at stage point with your friends?' reveal that respondents who responded 'YES' were 24 (40\%) while those who responded 'NO' were 36 (60\%). This implies that more respondents failed to keep physical distance than those who kept physical distance from other persons. It was practically difficult to keep physical distance especially during the riding. This can be mitigated by encouraging the wearing of protective clothes for both the rider and his/her passengers. Physical distancing is a very difficult health practice to observe especially during the riding on the bike itself. This is also observed on nearly all Kenya streets and roads as bike operators flout the rule by carrying more than capacity of the recommended one passenger. In Kenya keeping a physical distance of 1.5 metres away on a bike can only be realistic. There was laxity on part of law enforcement on social distancing.

Regarding the condition of physical distancing, Lamu (2020), posts that the Ugandan president Yoweri Museveni banned motorbikes from transporting passengers and only allowed them to carry goods. Nevertheless, an anticorona shield has been proposed to be installed on bikes for protection of both the operators and the passengers.

Responses on the question: ' Do you wash your hands after every trip you make?' reveal that respondents who responded 'YES' were 21 (35\%) while those who responded 'NO' were 39 (60\%). This implies that more respondents failed to wash hands than those who washed their hands after each trip. This could be attributed by the negligence of the riders as well as the public and the belief that corona was normal flu; they could get used to with time. This kind of behaviour may also arise from lack of adequate information on the pandemic. This situation may be mitigated through personal responsibility of the motorbike riders as well as their passengers. This finding on washing of hands was also observed by Namu (2020) in Nairobi where washing of hands points was created at market places at a cost especially in areas where water is scarce. Water was supplied by county governments in large markets free of charge. All people entering market places, hospitals, supermarkets, banks and offices were forced to wash hands before entry.
Responses on the question: ' Do you engage your customer in conversation while riding?' reveal that respondents who responded 'YES' were 28 (46.7\%) while those who responded 'NO' were 32 (53.3\%). This implies that more respondents never engaged their customers in conversation while riding than those who conversed with their passengers. This was positive however those who are fond of conversing with their passengers while riding was equally a big number. This kind of behaviour may also arise from lack of adequate information on how the pandemic may spread. It is easy for the rider to infect the passenger behind him through droplets of saliva or tears from the eyes of a speeding rider who has no protective clothes and head gear. This situation may be mitigated through personal responsibility of the motorbike riders as well as their passengers. Through personal observation, very few riders engage passengers while riding as this may also distract the focus of the operator on the road and may cause accidents. Many riders cause accidents when they are heavily engaged in conversations with their passengers.

Responses on the question: `Do you always maintain one passenger capacity at a time?' reveal that respondents who responded 'YES' were 14 (23.3\%) while those who responded 'NO' were 46 (76.7 \%). This implies that more respondents never adhered to bike capacity of one passenger than those who observed traffic rule of maintaining one passenger capacity every trip made. This was positive however those who flouted the traffic rule also endangered the lives of the passengers by exposing them to the risk of being infected by Covid-19 pandemic. This kind of behaviour may also arise from the laxity of the law enforcement agents. It is easy for the rider to infect the passengers who ride more than one passenger on a motor bike. This situation may be mitigated through personal responsibility of the motorbike riders as well as their passengers. The police should also enforce the laws strictly among the riders. This observation of flouting the rule to carry one passenger can be seen on most roads in Kenya away from police points. Sometimes operators give bribes to police to overlook on the common mistakes committed by the bike operators. The ministry of health in Kenya and that of transport (March 2020) observed the flouting of motorbike capacity rule during lockdown in the affected cities and more.

Responses on the question: 'Do you sanitize your passengers before the ride?' reveal that respondents who responded 'YES' were 15 (25\%) while those who responded 'NO' were 45 (75\%). This implies that more respondents never adhered to the rule of sanitization of their environment and customers than those who sanitized. This could imply that high levels of poverty among the operators denied them the ability to buy the sanitizers for their customers. They may have depended on donations from the county administration and other nongovernment agencies. However, some operators just flouted the ministry of health directive on Covid-19 pandemic since they used to do it. This kind of behaviour may also arise from the laxity of the law enforcement agents. It is easy for the rider to infect the passengers who ride more than one on a motor bike. This situation may be mitigated through personal responsibility of the motorbike riders as well as their passengers. The police should also enforce the laws strictly among the operators.

The finding on sanitization concur with the finding of Namu (2020) where good effort was recorded by county governments to provide sanitizer to the motorbike operators and watering tanks to be used free of charge. 


\section{Extent of Responses on Social Health Risk Behaviour Change}

Respondents were asked to indicate the extent to which they had observed social health hygiene practices such as avoiding greeting through handshake, use of protective gear, observe physical distance at stage point with friends, wash hands after every trip, engage your customer in conversation, maintain one passenger capacity at a time and sanitize your passengers before the ride. Table 3 shows the results.

TABLE 3: Extent of Post Responses on Social Health Risk Behaviour Change.

\begin{tabular}{|l|c|c|c|c|c|c|c|}
\hline \multicolumn{1}{|c|}{ STATEMENTS } & YES & \multicolumn{2}{|c|}{$\begin{array}{c}\text { Low } \\
\text { Extent }\end{array}$} & \multicolumn{2}{c|}{$\begin{array}{c}\text { Moderate } \\
\text { Extent }\end{array}$} & \multicolumn{2}{|c|}{$\begin{array}{c}\text { High } \\
\text { Extent }\end{array}$} \\
\hline Do you greet your friends through handshake? & 25 & 13 & $52 \%$ & 12 & $48 \%$ & & \\
\hline Do you use protective gear when riding? & 27 & 18 & $66.7 \%$ & 5 & $18.5 \%$ & 4 & $14.8 \%$ \\
\hline $\begin{array}{l}\text { Do you observe physical distance at stage point with } \\
\text { your friends? }\end{array}$ & 24 & 16 & $66.6 \%$ & 8 & $33.3 \%$ & & \\
\hline $\begin{array}{l}\text { Do you wash your hands after every trip you make? } \\
\text { Do you engage your customer in conversation while } \\
\text { riding }\end{array}$ & 21 & 5 & $23.9 \%$ & 16 & $76.1 \%$ & & \\
\hline $\begin{array}{l}\text { Do you always maintain one passenger capacity at a } \\
\text { time? }\end{array}$ & 14 & 7 & $50 \%$ & 7 & $50 \%$ & & \\
\hline \begin{tabular}{l} 
Do you sanitize your passengers before the ride? \\
\hline
\end{tabular} & 15 & 5 & $33.3 \%$ & 10 & $66.7 \%$ & & \\
\hline
\end{tabular}

Source: Field Data

Table 3 indicate the distribution the extent of positive responses on social health risk behaviour change. On greetings through handshake the overall 'YES' response was 25 of which at low extent respondents were 12 (52\%), while at moderate extent respondents were12 (48\%). Therefore, the YES responses at low extent were more than the moderate extent. This implies that it is difficult to sustain this practice of washing hands long and it may die out with time because it is embedded in the local people's culture especially when meeting the elderly rural folk. It may take a long time for it to disappear. In view of the Covid-19 pandemic this remains a challenge that call for high discipline and personal social responsibility.

The overall 'YES' response on protective gear were 27 of which at low extent, respondents were 18 (66.7\%), at moderate extent respondents were $5(18.5 \%)$ and at high extent 4 (14.8\%). Therefore, the YES responses at low extent were more than the moderate and high extent. This implies that the use of protective clothes may be a temporal measure to avoid police disturbance and has little use to do with combating the spread of Covid-19 pandemic. Given a leeway most operators may abandon the health practice.

The overall 'YES' response on the observation of physical distance were 24 of which at low extent, respondents were $16(66.7 \%)$ and at moderate extent respondents were 8 (33.3\%). Therefore, the YES responses at low extent were more than the moderate and high extent responses. This implies that the observation of physical distance may be a temporal measure to avoid police disturbance and has little use to help combat the spread of Covid-19 pandemic. The overall 'YES' responses on washing of hands with soap were 21 of which at low extent, respondents were $5(23.9$ $\%)$ and at moderate extent respondents were 16 (76.1\%). Therefore, the YES responses at low extent were fewer than the moderate extent responses. This implies that the washing of hands was a common and easy practice and may continue to help in combating the spread of Covid- 19 pandemic. The explanation is that it has been part of human culture to always wash hands before taking meals in most African communities.
The overall 'YES' response on engaging customers in a conversation were 28 of which at low extent, respondents were $12(42.9 \%)$ and at moderate extent respondents were $16(57.1 \%)$. Therefore the 'YES' responses at low extent were fewer than the moderate extent responses. This implies that most bike operators never engaged their customers in conversation during a ride and this was a positive behavioural practice to contain the spread the Covid-19 pandemic. The explanation is that it has been part of human culture for one to always converse with people especially those one is familiar with but not a very common one for strangers during the ride. For strangers it is not necessary to initiate a conversation. This may be a positive trend to help combat the spread of Covid-19 pandemic.

The overall 'YES' response on maintenance of one passenger capacity were 14 respondents of which at low extent, respondents were 7(50\%) and at moderate extent, respondents were 7 (50\%). Therefore, the YES responses at low extent and at the moderate extent responses were the same. This implies that the maintenance of one passenger capacity was averagely practiced among the operators. The explanation may have been that while riding on roads away from the police the traffic rules on capacity were always flouted by the riders. Riders only adhered to the rules with the presence of the police near them. This is a social health risk behaviour witnessed on most roads in Africa.

The 'YES' responses on sanitization of passengers were 15 respondents of which at low extent, respondents were $5(33.3 \%)$ and at moderate extent, respondents were 10 $(66.7 \%)$. Therefore, the YES responses at low extent were less than responses at the moderate extent. This implies that the sanitization was above averagely practiced among the operators. The explanation may have been that the county governments had provided water and sanitizers at every motor bike stage in the sub county and even in the entire Bungoma County free of charge. It was therefore easy for the practice to be maintained only at the stage points. 


\section{SUMMARY AND CONCLUSION}

The objective of the study was to investigate Covid-19 pandemic and its influence on social health risk behaviour change among the motor bike riders in Kimilili Sub county Bungoma Kenya. The results indicate that the compliance to the avoidance of greeting through handshake was at $41.7 \%$, use of protective clothes was at $45 \%$, keeping physical distance at $40 \%$, washing hands was at $35 \%$, conversation with passenger at $46.7 \%$, carrying per bike capacity at $23.9 \%$ and sanitization at $25 \%$. The extents of compliance to the social health rules were also unfortunately low. The results indicate that the avoidance of greeting through handshake was at low extent $52 \%$ and moderate extent $48 \%$, use of protective clothes was at low extent was $66.7 \%$, moderate extent $18.5 \%$ and high extent at $14.8 \%$, keeping physical distance was at low extent $66.7 \%$ and moderate extent at $33.3 \%$, washing hands was $23.9 \%$ at low extent and moderate extent at $76.1 \%$, conversation with passengers was at low extent $42.9 \%$ and moderate extent at $57.1 \%$, carrying capacity per bike at low extent $50 \%$ and moderate extent $50 \%$ and sanitization at low extent $25 \%$ and at moderate extent $75 \%$. Basing on the foregoing statistics areas that performed well in terms of compliance were: washing of hands at $76.1 \%$ moderate compliance, non-conversation with passenger $57.1 \%$ at moderate compliance, right carrying capacity $50 \%$ at moderate compliance and sanitization $66.7 \%$ at moderate compliance.

All the statistics for compliance to social health behaviour in view of the Covid- 19 pandemic was below $50 \%$ as those for social health risk behaviour recorded a higher score of $58.3 \%$. This implies that social health risk behaviour was still highly practised among the boda boda operators in Kimilili Sub County. In conclusion social health risk malpractice among the boda boda operators in Kimilili sub county was highly prevalent hence a hindrance against the government effort to fight against the spread of covid-19 pandemic in the region.

\section{RECOMMENDATIONS}

The study therefore recommends stringent measures to be taken up by the government to curb the spread of Covid19 pandemic through the following ways:

i) Provision of vital information and awareness among the boda boda operators.

ii) Encourage through sensitization programs on social health practices among the boda boda operators such avoidance of handshakes and wearing of protective clothes.

iii) Devise ways of shielding bike operators and their passengers while riding through some form of training.

iv) Strict police surveillance will deter the criminal tendencies of flouting the rules such as the violation of the bike carrying capacity rule.

v) Lastly the national government as well as the county governments should continue to support motorbike operators in terms of provision of of protective clothes and sanitizers.

\section{REFERENCES}

[1] Agutu, N. (2020). Mutua Bans Boda boda Weak Link to Curb the Spread of Corona virus. Retrieved at https://www.the.star.co.ke.>covid-19 72

[2] Irandu, M.E. (2020). Transportation in Kenya, The Weak Link in the Fight of Covid-19: Nairobi. Retrieved at https://uonresearch.org.>blog>transport.

[3] Kimuyu, w.h. (march $30^{\text {th }}, 2020$ ). Nairobi news: Kenya takes drastic steps to tame Covid-19 spread by bodaboda operators.

[4] Kumar, A. (2011). Understanding Emerging Role of Motorcycles in African Cities. Retrieved at https://openknowledge.worldbank.org.

[5] Lamu, D. (July 21, 2020). Government talks with boda boda over anti-corona shield. Retrieved at Ministry of health (Thursday, April 9th 2020). Government warn boda boda riders flouting rules: Nairobi. Retrieved at https://www.health.go.ke.government.

[6] Namu. J. A. (April 18th 2020). Covid-19 in Africa: To Eat or to Heal? Retrieved from https://www.theelephant.info>2020-07-24

[7] National Crime Research Centre report. (2018). Boda boda Motorcycle Transport and Security Challenges in Kenya. Nairobi: Jomo Kenyatta Foundation. 